\title{
Selective Room-Temperature Hydrogenation of Amides to Amines and Alcohols Catalyzed by a Ruthenium Pincer Complex and Mechanistic Insight
}

\author{
Sayan Kar, Michael Rauch, Amit Kumar, Gregory Leitus, Yehoshoa Ben-David, and David Milstein*
}

Cite This: ACS Catal. 2020, 10, 5511-5515

Read Online

ACCESS |

LIII Metrics \& More

Article Recommendations

Supporting Information

ABSTRACT: We report a room-temperature protocol for the hydrogenation of various amides to produce amines and alcohols. Compared with most previous reports for this transformation, which use high temperatures (typically, $100-200{ }^{\circ} \mathrm{C}$ ) and $\mathrm{H}_{2}$ pressures $(10-100 \mathrm{bar}$ ), this system proceeds under extremely mild conditions (RT, 5-10 bar of $\mathrm{H}_{2}$ ). The hydrogenation is catalyzed by well-defined ruthenium-PNNH pincer complexes $(0.5 \mathrm{~mol} \%)$ with potential dual modes of metal-ligand cooperation. An unusual Ru-amidate complex was formed and crystallographically characterized. Mechanistic investigations indicate that the room-temperature hydrogenation proceeds predominantly via the $\mathrm{Ru}-\mathrm{N}$ amido/amine metal-ligand cooperation.

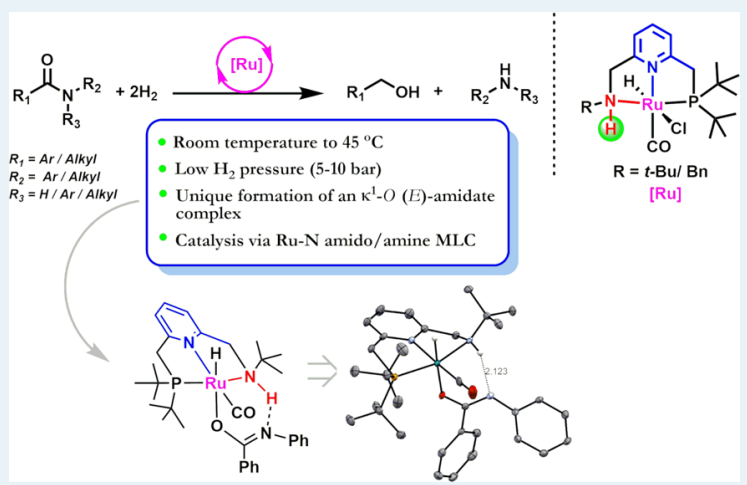

KEYWORDS: amide, hydrogenation, metal-ligand cooperation, ruthenium-pincer, room-temperature, ruthenium amidate complex

R eduction of the amide group has useful applications in diverse areas of chemical transformations including synthesis of amines, alcohols, peptide chemistry, total synthesis, $\mathrm{CO}_{2}$ recycling, and others. ${ }^{1,2}$ The traditional methods to reduce amides are noncatalytic and use stoichiometric amounts of hydride reducing agents, thus producing a stoichiometric amount of waste. ${ }^{3}$ In this context, development of efficient catalytic hydrogenation systems for their reduction is desirable. ${ }^{4}$ While hydrogenations of amides have been reported, they are more challenging than that of most other carboxylic derivatives because of the low electrophilic character of the amide carbonyl group. ${ }^{5}$

Amide hydrogenation can proceed either via $\mathrm{C}-\mathrm{N}$ bond cleavage or by $\mathrm{C}-\mathrm{O}$ bond cleavage (Scheme 1$).{ }^{5 \mathrm{a}, \mathrm{b}}$ We are particularly interested in the $\mathrm{C}-\mathrm{N}$ bond cleavage pathway, which is challenging because of the water losing tendency of the hemiaminal intermediate to form imine. The first example

Scheme 1. Two Possible Pathways of Amide Hydrogenation

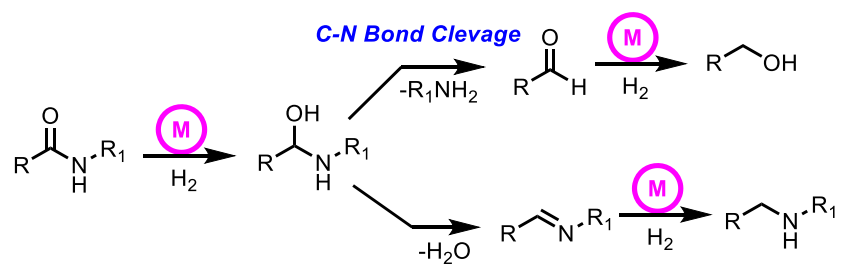

C-O Bond Clevage of amide hydrogenation with $\mathrm{C}-\mathrm{N}$ bond cleavage appeared in $2010^{6 a}$ followed by reports of several other research groups. ${ }^{6}$ Hydrogenation and dehydrogenative formation of the amide bond has also been instrumental in the recent development of promising liquid organic hydrogen carrier (LOHC) systems based on alcohols and amines. ${ }^{7}$ However, the reported hydrogenation reactions require harsh reaction conditions (typically $100-150{ }^{\circ} \mathrm{C}$ and/or $10-100$ bar of $\mathrm{H}_{2}$ pressure). In this regard, amide hydrogenation protocols to form amines and alcohols under mild conditions are clearly required. Development of such protocols would also facilitate the development of low-temperature amide-based LOHC systems as well as lowtemperature $\mathrm{CO}_{2}$ recycling to methanol systems. ${ }^{8}$

Saito and co-workers have reported an example of $\mathrm{Ru}-$ catalyzed dimethylformamide hydrogenation at $60{ }^{\circ} \mathrm{C}$ under high $\mathrm{H}_{2}$ pressure of $80 \mathrm{bar},{ }^{6 \mathrm{k}}$ but higher temperature $\left(120^{\circ} \mathrm{C}\right)$ was required at lower $\mathrm{H}_{2}$ pressures $(20 \mathrm{bar})$ to obtain similar yields (60\%). Langer and co-workers reported examples of amide hydrogenation at $70{ }^{\circ} \mathrm{C}$ with an iron complex using high catalyst loading $(10 \mathrm{~mol} \%)$ at 50 bar $\mathrm{H}_{2}{ }^{6 \mathrm{~g}}$ however, this interesting system exhibited limited scope and required $100{ }^{\circ} \mathrm{C}$

Received: March 26, 2020

Revised: April 20, 2020

Published: April 21, 2020 
for completion at lower catalyst loadings $(2 \mathrm{~mol} \%)$. Recently, Beller and co-workers reported a Mo-pincer catalyzed amide hydrogenation at $80{ }^{\circ} \mathrm{C}$, but this system employed high $\mathrm{H}_{2}$ pressure (50 bar) and the substrate scope was synthetically limited to $N$-methylphenylformamides. ${ }^{\text {f }}$ Bergens reported asymmetric hydrogenolysis of some specific functionalized $\alpha$ phenoxy amides at RT and low pressure, but the system requires high catalyst loading $(10 \mathrm{~mol} \%)$ and more than stoichiometric amounts of strong base $(120-250 \mathrm{~mol} \%$ of $t$ $\mathrm{BuOK} / i-\mathrm{PrONa}$ ) for effective catalysis. ${ }^{6 \mathrm{p}}$

As a part of our ongoing research endeavor, we seek to develop metal complexes to facilitate (de)hydrogenation reactions under mild conditions. To this extent, we have reported a new class of pincer complexes (based on PNNH ligands) where dual modes of metal ligand cooperation (MLC) are possible (via ligand dearomatization and metal amido bond formation) (Figure 1). ${ }^{7 e, 9}$ Here, we report a system for room-

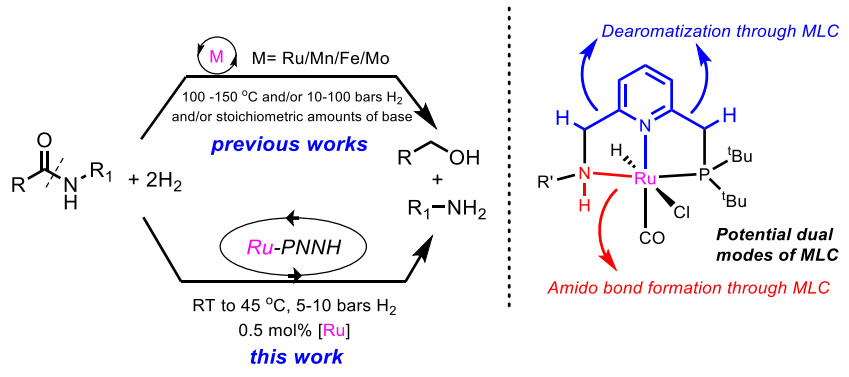

Figure 1. Amide hydrogenation reported here as compared with previous reports.

temperature amide hydrogenation to amines and alcohols catalyzed by the Ru-PNNH complexes at low catalyst loading ( $0.5 \mathrm{~mol} \%$ ) under low $\mathrm{H}_{2}$ pressures (5-10 bar).

We started our investigation with benzanilide as the model substrate (Table 1). When benzanilide in THF was subjected to hydrogenation $\left(10\right.$ bar of $\mathrm{H}_{2}$ ) at $45{ }^{\circ} \mathrm{C}$ with complex $\mathrm{Ru}-$ $\mathrm{PNN}^{t B u} \mathrm{H}(\mathbf{R u}-1 ; 0.5 \mathrm{~mol} \%)$ as the precatalyst in the presence of catalytic $t$-BuOK ( $2 \mathrm{~mol} \%), 67 \%$ of amide conversion was observed by GC after $20 \mathrm{~h}$ (entry 1). We observed the formation of benzyl alcohol and aniline as the reaction products by GC-MS, revealing the $\mathrm{C}-\mathrm{N}$ bond cleavage to be the favorable pathway under the reaction conditions. Changing the $\mathrm{N}$-substitution of the catalyst from $t$-Bu to benzyl group (Ru-2), the catalytic activity increased even further, and complete conversion of the amide to the amine and alcohol was observed after $20 \mathrm{~h}$ (entry 2). However, changing the $\mathrm{P}$ substitution of the $\mathrm{PNNH}$ ligand from $t$-Bu to $\mathrm{Ph}$ ( $\mathbf{R u}-3$ ) resulted in a significant decrease in the catalytic activity (entry 3). The traditional $\mathrm{Ru}-\mathrm{PNN}^{E t}$ catalyst $\mathrm{Ru}-4$, lacking a $\mathrm{N}-\mathrm{H}$ bond, was unable to efficiently catalyze the hydrogenation at $45{ }^{\circ} \mathrm{C}$ (entry 4). With Ru-2, the hydrogenation can proceed to completion within $20 \mathrm{~h}$ even at the lower temperature of $35^{\circ} \mathrm{C}$ (entry 5). Furthermore, full conversion of benzanilide to benzyl alcohol and aniline can be obtained even at RT (19-24 $\left.{ }^{\circ} \mathrm{C}\right)$, although a longer reaction time $(68 \mathrm{~h})$ is required (entries $6-7)$. Toluene is not as good a solvent as THF for this hydrogenation, possibly because of the limited solubility of benzanilide in toluene (entry 8 ).

Subsequently, we explored the substrate scope of this catalytic hydrogenation of amides under mild conditions (Table 2). Several substituted benzanilides were quantitatively converted to the corresponding alcohol and aniline at RT
Table 1. Optimization of Catalytic Hydrogenation of Benzanilide $^{a}$

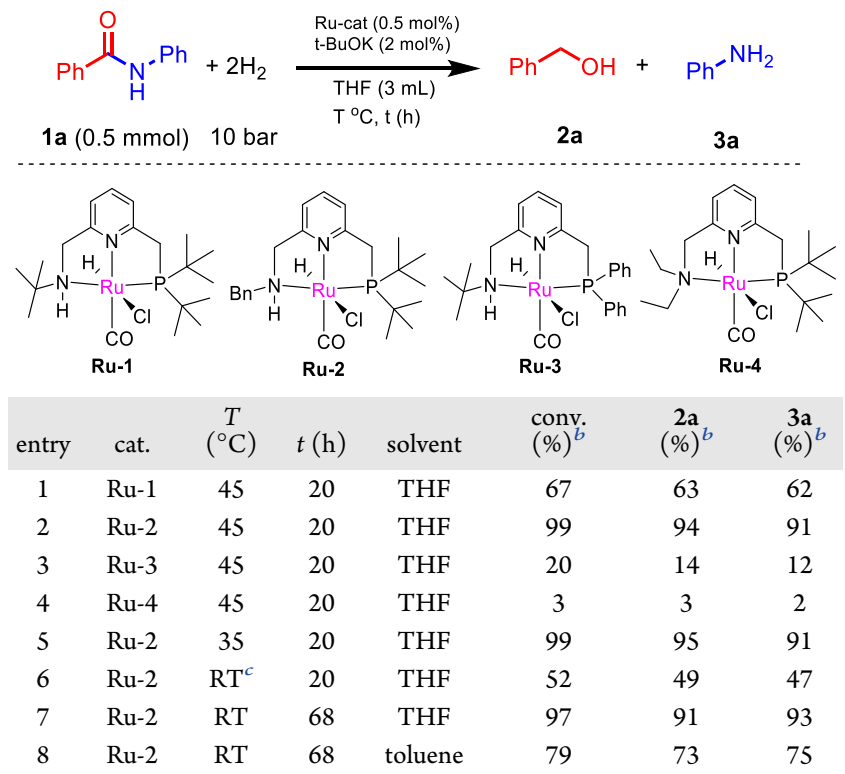

${ }^{a}$ Reaction conditions: benzanilide $(0.5 \mathrm{mmol})$, cat. $(0.5 \mathrm{~mol} \%), t$ $\operatorname{BuOK}(2 \mathrm{~mol} \%)$, THF ( $3 \mathrm{~mL}), \mathrm{H}_{2}$ (10 bar at RT), $T$ (as specified, bath temperature), $t$ (as specified). ${ }^{b}$ Conversions and yields are determined by GC with mesitylene as an internal standard. ${ }^{c} \mathrm{RT}=$ room temperature $\left(19-24^{\circ} \mathrm{C}\right)$

(under 10 bar $\mathrm{H}_{2}$ ) with catalyst Ru-2 (entries 1-6). Formamides, such as $\mathrm{N}$-(4-chlorophenyl)formamide, $\mathrm{N}$-(4methylphenyl)formamide can also be hydrogenated at room temperature to the corresponding amine and methanol (entry 7-8). Other amides, such as $N$-acetylmorpholine; $N, N$ diphenylbenzamide; $N$-acetylaniline; $N$-hexylbenzamide; $N$ phenyloctanamide; $N$-benzylformamide; and $N$-heptyloctanamide were hydrogenated at either RT or at a slightly elevated temperature of $35-45{ }^{\circ} \mathrm{C}$ (entries 9-15), which is still significantly lower than the hydrogenation temperature reported previously with other catalysts.

Next, we carried out mechanistic investigations to further understand the high catalytic activity of the Ru-PNNH complexes compared to the traditional $\mathrm{PNN}^{E t}$ complex Ru-4. Upon addition of 2 equiv of $t$-BuOK to a solution of complex Ru-1 (dissolved in THF), an intensely purple-colored solution of the anionic ruthenium enamido complex $\mathbf{R u - 1 A}$ was formed. ${ }^{9 \mathrm{~d}}$ Upon addition of two equiv of benzanilide to this solution, the intense purple color disappeared to produce a light-green solution, and the ${ }^{31} \mathrm{P}$ NMR spectrum exhibited only a single peak at $108.5 \mathrm{ppm}$ (Figure S13). This is due to the formation of the ruthenium amidate complex Ru-1B, which was characterized by ${ }^{1} \mathrm{H},{ }^{31} \mathrm{P}$, and ${ }^{13} \mathrm{C}$ NMR spectroscopy (Scheme 2a, Figures S8-S11) and a single-crystal X-ray diffraction study (see SI). As exhibited by the crystal structure, the amidate ligand displays $\kappa^{1}-\mathrm{O}$ binding to the $\mathrm{Ru}$ metal center, which is uncommon for late transition metal complexes and, to the best of our knowledge, has not been observed previously in ruthenium amidate complexes. ${ }^{10}$ The $\kappa^{1}-O$ geometry is also characterized by an elongated $\mathrm{C}-\mathrm{O}$ bond length $(1.279 \AA)$ and a shortened $\mathrm{C}-\mathrm{N}$ bond length $(1.307 \AA)$ of the amidate ligand as compared to free benzanilide (1.227 and $1.363 \AA$, respectively, for $\mathrm{C}-\mathrm{O}$ and $\mathrm{C}-\mathrm{N}$ bond). ${ }^{11}$ Furthermore, the coordinated $(E)$ isomer of $\kappa^{1}-O$ Ru-1B was 
Table 2. Hydrogenation of Various Amides at or Near $\mathrm{RT}^{\S}$

Entry

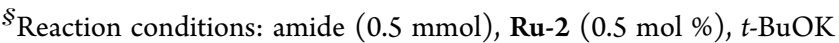
( $2 \mathrm{~mol} \%)$, THF ( $3 \mathrm{~mL}), \mathrm{H}_{2}$ (10 bar at RT), $T$ (as specified), $t$ (68 h). ${ }^{a}$ Conversions and yields were determined by GC with mesitylene as an internal standard. Products were characterized by GC-MS. ${ }^{b}$ Yield determined by ${ }^{1} \mathrm{H}$ NMR. ${ }^{c}$ Yields of methanol and ethanol are lower than that of the corresponding amine due to volatility. ${ }^{d}$ With catalyst Ru-1 (0.5 mol \%), $\mathrm{H}_{2}$ (5 bar), $t(20 \mathrm{~h})$.

observed in the structure, which is rare in any late transition metal $\kappa^{1}-O$ amidate complex due to steric reasons. ${ }^{10}$ Interestingly, the $\mathrm{N}-\mathrm{H}$ proton of the $\mathrm{PNNH}$ ligand and the $\mathrm{N}$ atom of the amidate ligand are aligned in close spatial proximity $(2.123 \AA)$ with the possibility of a hydrogen bonding interaction, thus providing additional stability to $\mathbf{R u}-\mathbf{1 B}$. Indeed, in the ${ }^{1} \mathrm{H}$ NMR spectrum of $\mathbf{R u}-\mathbf{1 B}$, the chemical shift of the $\mathrm{N}-H$ proton is strongly downfield shifted $(\sim 10.5$ $\mathrm{ppm}$ ), indicating hydrogen bonding in solution (Figure S8).
Scheme 2. Mechanistic Reactions
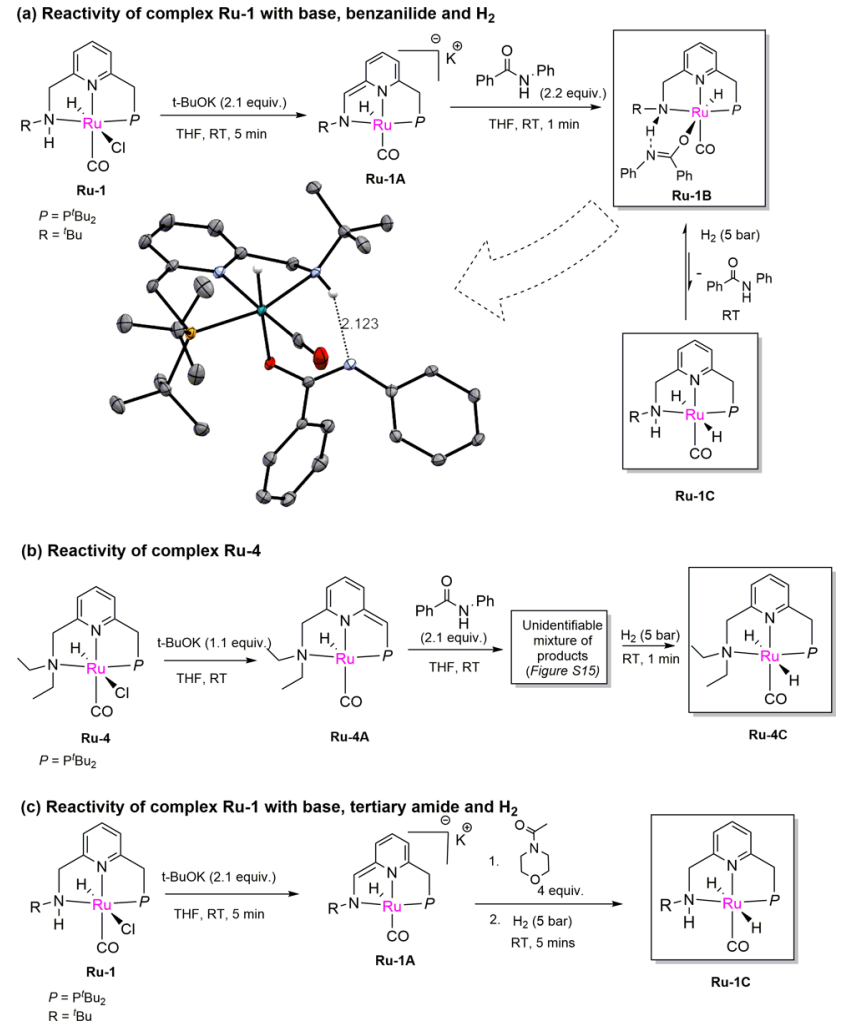

The hydrogen bonding is crucial to the formation of the $\kappa^{1}-O$ (E)-amidate complex as the analogous amidate complex of $\mathbf{R u}$ 4 lacking an $\mathrm{N}-\mathrm{H}$ bond, was not observed under similar conditions (Scheme 2b). Notably, a somewhat similar amidate complex has been observed by Bernskoetter, Hazari, and coworkers in a Fe-PNP system, although with $\kappa^{1}-N$ coordination. ${ }^{6 \mathrm{i}}$

Formation of the amidate complex, while interesting, is offcycle and may also somewhat decrease the catalytic efficiency in the hydrogenation of the secondary amides. Ru-1B undergoes rapid dissociation and reassociation of the amide in solution, as verified by an amide exchange experiment (Figure S20). Under 5 bar of $\mathrm{H}_{2}$ pressure, complex $\mathbf{R u - 1 B}$ is in equilibrium with the dihydride complex Ru-1C (Scheme 2a, Scheme S1). This equilibrium favors the amidate complex Ru$1 B$ (Figure S13, panel 4). The equilibrium can also be indirectly observed in the presence of $\mathrm{D}_{2}$, in which case rapid suppression of the $\mathrm{N}-\mathrm{H}$ proton and one of the $\mathrm{P}-\mathrm{CH}_{2}$ protons of Ru-1B was observed due to H/D scrambling (Figure S18S19). To probe the resting state of the catalyst during the reaction, we conducted a control catalytic hydrogenation experiment in an NMR tube with $\mathbf{R u - 1 B}$ as catalyst using 5 equiv of benzanilide substrate under 5 bar $\mathrm{H}_{2}$. Monitoring the reaction progress at $45{ }^{\circ} \mathrm{C}$, only the amidate complex Ru-1B was observed in the solution while the dihydride complex was not observed (Figure S14). Thus, complex Ru-1B acts as the catalytic resting state during the reaction.

Returning to the reactivity of the enamido complex Ru-1A, upon addition of a substrate lacking a $\mathrm{N}-\mathrm{H}$ proton, such as $\mathrm{N}$ acetylmorpholine, the solution of complex $\mathbf{R u}-\mathbf{1 A}$ remained purple even after the addition of 4 equiv of amide. No formation of any new complex was observed by NMR spectroscopy. After the reaction was pressurized with 5 bar 
of $\mathrm{H}_{2}$, immediate formation of the dihydride complex was observed at RT (Scheme 2c; Figure S16). The dihydride peaks remained the major peak in both ${ }^{31} \mathrm{P}$ and ${ }^{1} \mathrm{H}$ NMR spectra until completion of the hydrogenation, indicating that the reaction of the amide with the dihydride complex is the ratedetermining step in the catalytic cycle (vide infra, Scheme 3).

Scheme 3. Plausible Mechanistic Cycle

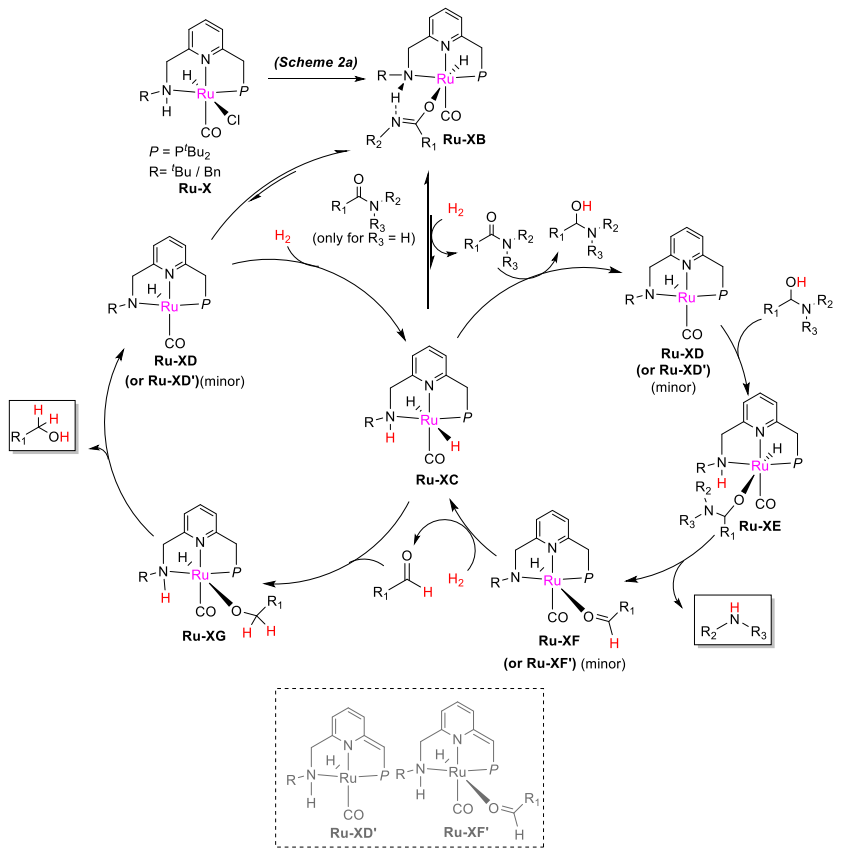

On the basis of these insights and prior investigations reported, we propose a catalytic cycle as depicted in Scheme 3..$^{6 a, k, 9 a, 12}$ For amides bearing an $\mathrm{N}-\mathrm{H}$ proton, the catalytic resting state is the amidate complex $\mathbf{R u}-\mathbf{X B}$. In the presence of $\mathrm{H}_{2}$, Ru-XB forms the dihydride $\mathbf{R u}-\mathbf{X C}$, which through hydride attack on the amide carbonyl group and proton abstraction of the $\mathrm{N}-\mathrm{H}$ group of the $\mathrm{PNNH}$ ligand forms the hemiaminal, along with the intermediate complex Ru-XD. This step can also occur via proton abstraction from the $\mathrm{CH}_{2}$ group of the $P$ side arm instead of the $\mathrm{N}-\mathrm{H}$ group (to generate $\mathbf{R u}-\mathbf{X D}^{\prime}$ ). However, this pathway does not significantly contribute to the overall hydrogenation at lower temperatures (RT to $45{ }^{\circ} \mathrm{C}$ ) (compare the hydrogenation activity of $\mathbf{R u - 1 / R \mathbf { u } - 2}$ with that of $\mathbf{R u}-4)$. It is likely that the acidic nature of the $\mathrm{N}-\mathrm{H}$ proton of $\mathrm{PNNH}$ ligand assists in lowering the energy requirement of this rate-determining step, thus allowing the hydrogenation to proceed even at RT via the amido pathway. This can also explain the higher catalytic activity of Ru-2 compared with $\mathbf{R u}$ 1 , where the $B n$ substitution of the $\mathrm{N}$ donor atom makes the ligand $\mathrm{N}-H$ of $\mathbf{R u}-\mathbf{2}$ less basic as compared with $\mathbf{R u}-\mathbf{1}$ with $t-B u$ group in the $\mathrm{N}$ atom. Alternatively, the lower steric bulk of the benzyl group can also contribute to the observed increased hydrogenation rate of $\mathbf{R u}-\mathbf{2}$ compared to $\mathbf{R u}-\mathbf{1}$. Subsequently, the hemiaminal quickly binds to the ruthenium center to form the hemiaminoxy complex Ru-XE, which, through a proton abstraction from the ligand, releases an amine molecule with concomitant formation of the aldehyde complex Ru-XF (or $\mathbf{R u}-\mathbf{X F}^{\prime}$ ). Dissociation of the weakly coordinating aldehyde from $\mathrm{Ru}$ center, followed by the $\mathrm{H}_{2}$ splitting across the $\mathrm{Ru}-\mathrm{N}$ bond generates the dihydride complex Ru-XC. Outer-sphere hydride transfer from $\mathbf{R u}-\mathbf{X C}$ to the aldehyde then forms the alkoxy complex Ru-XG, which releases an alcohol molecule, generating the amido complex Ru-XD or the dearomatized complex Ru-XD'. Ru-XD (or $\mathbf{R u}-\mathbf{X D}^{\prime}$ ) then binds another amide molecule to regenerate the amidate complex Ru-XB. In case of a tertiary amide, the hydrogenation proceeds through a similar pathway but without the involvement of $\mathrm{Ru}$-amidate complex.

In conclusion, selective hydrogenation of amides to alcohols and amines is reported at $\mathrm{RT}$ under mild $\mathrm{H}_{2}$ pressure. The ruthenium-PNNH complexes display excellent catalytic activity in this hydrogenation. The high activity of $\mathrm{Ru}-\mathrm{PNNH}$ complexes is due to the MLC pathway via $\mathrm{Ru}-\mathrm{N}$ amido/ amine pathway. Using Ru-2 as the catalyst, a series of amides were hydrogenated at, or near, RT under 5-10 bar of $\mathrm{H}_{2}$ pressure. We believe that this protocol can facilitate the development of $\mathrm{CO}_{2}$ recycling (via hydrogenation) as well as LOHC systems that may operate at considerably lower temperatures $\left(<50{ }^{\circ} \mathrm{C}\right)$ compared with the existing ones. Both avenues are currently being explored in our group.

\section{ASSOCIATED CONTENT}

\section{SI Supporting Information}

The Supporting Information is available free of charge at https://pubs.acs.org/doi/10.1021/acscatal.0c01406.

General information and experimental details (PDF)

$\mathrm{X}$-ray data for amidate complex (CIF)

\section{AUTHOR INFORMATION}

\section{Corresponding Author}

David Milstein - Department of Organic Chemistry, Weizmann Institute of Science, Rehovot 76100, Israel; 이잉.org/00000002-2320-0262; Email: david.milstein@weizmann.ac.il

\section{Authors}

Sayan Kar - Department of Organic Chemistry, Weizmann Institute of Science, Rehovot 76100, Israel

Michael Rauch - Department of Organic Chemistry, Weizmann Institute of Science, Rehovot 76100, Israel

Amit Kumar - Department of Organic Chemistry, Weizmann Institute of Science, Rehovot 76100, Israel

Gregory Leitus - Department of Chemical Research Support, Weizmann Institute of Science, Rehovot 76100, Israel

Yehoshoa Ben-David - Department of Organic Chemistry, Weizmann Institute of Science, Rehovot 76100, Israel

Complete contact information is available at:

https://pubs.acs.org/10.1021/acscatal.0c01406

\section{Notes}

The authors declare no competing financial interest.

\section{ACKNOWLEDGMENTS}

This research was supported by the European Research Council (ERC AdG 692775). D.M. holds the Israel Matz Professorial Chair of Organic Chemistry. S.K. acknowledges the Sustainability and Energy Research Initiative (SAERI) of the Weizmann Institute of Science for a research fellowship. M.R. acknowledges the Zuckerman STEM Leadership Program for a research fellowship.

\section{REFERENCES}

(1) Hudlicky, M. Reductions in Organic Chemistry; Ellis Horwood Ltd.: Chichester, U.K., 1984; pp 164-172. 
(2) Andersson, P. G.; Munslow, I. J. Modern Reduction Methods; Wiley: New York, 2008; p 423.

(3) Seyden-Penne, J. Reductions by the Alumino- and Borohydrides in Organic Synthesis, 2nd ed.; Wiley: New York, 1997; pp 1-13.

(4) (a) Gunanathan, C.; Milstein, D. Bond Activation and Catalysis by Ruthenium Pincer Complexes. Chem. Rev. 2014, 114, 1202412087. (b) Filonenko, G. A.; van Putten, R.; Hensen, E. J. M.; Pidko, E. A. Catalytic (de)hydrogenation promoted by non-precious metals - Co, Fe and Mn: recent advances in an emerging field. Chem. Soc. Rev. 2018, 47, 1459-1483.

(5) (a) Smith, A. M.; Whyman, R. Review of Methods for the Catalytic Hydrogenation of Carboxamides. Chem. Rev. 2014, 114, 5477-5510. (b) Pritchard, J.; Filonenko, G. A.; van Putten, R.; Hensen, E. J. M.; Pidko, E. A. Heterogeneous and homogeneous catalysis for the hydrogenation of carboxylic acid derivatives: history, advances and future directions. Chem. Soc. Rev. 2015, 44, 3808-3833. (c) Chardon, A.; Morisset, E.; Rouden, J.; Blanchet, J. Recent Advances in Amide Reductions. Synthesis 2018, 50, 984-997. (d) Zhou, Y.; Khan, R.; Fan, B.; Xu, L. Ruthenium-Catalyzed Selective Reduction of Carboxylic Esters and Carboxamides. Synthesis 2019, 51, 2491-2505.

(6) (a) Balaraman, E.; Gnanaprakasam, B.; Shimon, L. J. W.; Milstein, D. Direct Hydrogenation of Amides to Alcohols and Amines under Mild Conditions. J. Am. Chem. Soc. 2010, 132, 16756-16758. (b) John, J. M.; Bergens, S. H. A Highly Active Catalyst for the Hydrogenation of Amides to Alcohols and Amines. Angew. Chem., Int. Ed. 2011, 50, 10377-10380. (c) Ito, M.; Ootsuka, T.; Watari, R.; Shiibashi, A.; Himizu, A.; Ikariya, T. Catalytic Hydrogenation of Carboxamides and Esters by Well-Defined Cp* Ru Complexes Bearing a Protic Amine Ligand. J. Am. Chem. Soc. 2011, 133, 4240-4242. (d) Miura, T.; Held, I. E.; Oishi, S.; Naruto, M.; Saito, S. Catalytic hydrogenation of unactivated amides enabled by hydrogenation of catalyst precursor. Tetrahedron Lett. 2013, 54, 2674-2678. (e) Cabrero-Antonino, J. R.; Alberico, E.; Drexler, H.-J.; Baumann, W.; Junge, K.; Junge, H.; Beller, M. Efficient Base-Free Hydrogenation of Amides to Alcohols and Amines Catalyzed by WellDefined Pincer Imidazolyl-Ruthenium Complexes. ACS Catal. 2016, 6, 47-54. (f) Garg, J. A.; Chakraborty, S.; Ben-David, Y.; Milstein, D. Unprecedented iron-catalyzed selective hydrogenation of activated amides to amines and alcohols. Chem. Commun. 2016, 52, 52855288. (g) Schneck, F.; Assmann, M.; Balmer, M.; Harms, K.; Langer, R. Selective Hydrogenation of Amides to Amines and Alcohols Catalyzed by Improved Iron Pincer Complexes. Organometallics 2016, 35, 1931-1943. (h) Shi, L.; Tan, X.; Long, J.; Xiong, X.; Yang, S.; Xue, P.; Lv, H.; Zhang, X. Direct Catalytic Hydrogenation of Simple Amides: A Highly Efficient Approach from Amides to Amines and Alcohols. Chem. - Eur. J. 2017, 23, 546-548. (i) Jayarathne, U.; Zhang, Y.; Hazari, N.; Bernskoetter, W. H. Selective Iron-Catalyzed Deaminative Hydrogenation of Amides. Organometallics 2017, 36, 409-416. (j) Papa, V.; Cabrero-Antonino, J. R.; Alberico, E.; Spanneberg, A.; Junge, K.; Junge, H.; Beller, M. Efficient and selective hydrogenation of amides to alcohols and amines using a well-defined manganese-PNN pincer complex. Chem. Sci. 2017, 8, 3576-3585. (k) Miura, T.; Naruto, M.; Toda, K.; Shimomura, T.; Saito, S. Multifaceted catalytic hydrogenation of amides via diverse activation of a sterically confined bipyridine-ruthenium framework. Sci. Rep. 2017, 7, 1586. (1) Leischner, T.; Artús Suarez, L.; Spannenberg, A.; Junge, K.; Nova, A.; Beller, M. Highly selective hydrogenation of amides catalysed by a molybdenum pincer complex: scope and mechanism. Chem. Sci. 2019, 10, 10566-10576. (m) Kar, S.; Goeppert, A.; Kothandaraman, J.; Prakash, G. K. S. ManganeseCatalyzed Sequential Hydrogenation of $\mathrm{CO}_{2}$ to Methanol via Formamide. ACS Catal. 2017, 7, 6347-6351. (n) Kar, S.; Sen, R.; Kothandaraman, J.; Goeppert, A.; Chowdhury, R.; Munoz, S. B.; Haiges, R.; Prakash, G. K. S. Mechanistic Insights into RutheniumPincer-Catalyzed Amine-Assisted Homogeneous Hydrogenation of $\mathrm{CO}_{2}$ to Methanol. J. Am. Chem. Soc. 2019, 141, 3160-3170. (o) Kar, S.; Goeppert, A.; Prakash, G. K. S. Catalytic Homogeneous Hydrogenation of $\mathrm{CO}$ to Methanol via Formamide. J. Am. Chem.
Soc. 2019, 141, 12518-12521. (p) Rasu, L.; John, J. M.; Stephenson, E.; Endean, R.; Kalapugama, S.; Clément, R.; Bergens, S. H. Highly Enantioselective Hydrogenation of Amides via Dynamic Kinetic Resolution Under Low Pressure and Room Temperature. J. Am. Chem. Soc. 2017, 139, 3065-3071.

(7) (a) Hu, P.; Fogler, E.; Diskin-Posner, Y.; Iron, M. A.; Milstein, D. A novel liquid organic hydrogen carrier system based on catalytic peptide formation and hydrogenation. Nat. Commun. 2015, 6, 6859. (b) Xie, Y.; Hu, P.; Ben-David, Y.; Milstein, D. A Reversible Liquid Organic Hydrogen Carrier System Based on Methanol-Ethylenediamine and Ethylene Urea. Angew. Chem., Int. Ed. 2019, 58, 51055109. (c) Hu, P.; Ben-David, Y.; Milstein, D. Rechargeable Hydrogen Storage System Based on the Dehydrogenative Coupling of Ethylenediamine with Ethanol. Angew. Chem., Int. Ed. 2016, 55, 1061-1064. (d) Kothandaraman, J.; Kar, S.; Sen, R.; Goeppert, A.; Olah, G. A.; Prakash, G. K. S. Efficient Reversible Hydrogen Carrier System Based on Amine Reforming of Methanol. J. Am. Chem. Soc. 2017, 139, 2549-2552. (e) Kumar, A.; Janes, T.; Espinosa-Jalapa, N. A.; Milstein, D. Selective Hydrogenation of Cyclic Imides to Diols and Amines and Its Application in the Development of a Liquid Organic Hydrogen Carrier. J. Am. Chem. Soc. 2018, 140, 7453-7457. (f) Suárez, A., Hydrogenation of carbonyl compounds of relevance to hydrogen storage in alcohols. In Phys. Sci. Rev., 2018; Vol. 3; DOI: 10.1515/psr-2017-0028 (g) Shao, Z.; Li, Y.; Liu, C.; Ai, W.; Luo, S.-P.; Liu, Q. Reversible interconversion between methanoldiamine and diamide for hydrogen storage based on manganese catalyzed (de)hydrogenation. Nat. Commun. 2020, 11, 591.

(8) (a) Rezayee, N. M.; Huff, C. A.; Sanford, M. S. Tandem Amine and Ruthenium-Catalyzed Hydrogenation of $\mathrm{CO}_{2}$ to Methanol. J. Am. Chem. Soc. 2015, 137, 1028-1031. (b) Kothandaraman, J.; Goeppert, A.; Czaun, M.; Olah, G. A.; Prakash, G. K. S. Conversion of $\mathrm{CO}_{2}$ from Air into Methanol Using a Polyamine and a Homogeneous Ruthenium Catalyst. J. Am. Chem. Soc. 2016, 138, 778-781. (c) Kar, S.; Goeppert, A.; Prakash, G. K. S. Integrated $\mathrm{CO}_{2}$ Capture and Conversion to Formate and Methanol: Connecting Two Threads. Acc. Chem. Res. 2019, 52, 2892-2903.

(9) (a) Kumar, A.; Janes, T.; Espinosa-Jalapa, N. A.; Milstein, D. Manganese Catalyzed Hydrogenation of Organic Carbonates to Methanol and Alcohols. Angew. Chem., Int. Ed. 2018, 57, 1207612080. (b) Kumar, A.; Espinosa-Jalapa, N. A.; Leitus, G.; DiskinPosner, Y.; Avram, L.; Milstein, D. Direct Synthesis of Amides by Dehydrogenative Coupling of Amines with either Alcohols or Esters: Manganese Pincer Complex as Catalyst. Angew. Chem., Int. Ed. 2017, 56, 14992-14996. (c) Kumar, A.; Daw, P.; Espinosa-Jalapa, N. A.; Leitus, G.; Shimon, L. J. W.; Ben-David, Y.; Milstein, D. $\mathrm{CO}_{2}$ activation by manganese pincer complexes through different modes of metal-ligand cooperation. Dalton Transactions 2019, 48, 1458014584. (d) Fogler, E.; Garg, J. A.; Hu, P.; Leitus, G.; Shimon, L. J. W.; Milstein, D. System with Potential Dual Modes of Metal-Ligand Cooperation: Highly Catalytically Active Pyridine-Based PNNH-Ru Pincer Complexes. Chem. - Eur. J. 2014, 20, 15727-15731.

(10) Drover, M. W.; Love, J. A.; Schafer, L. L. 1,3-N,O-Complexes of late transition metals. Ligands with flexible bonding modes and reaction profiles. Chem. Soc. Rev. 2017, 46, 2913-2940.

(11) Bowes, K. F.; Glidewell, C.; Low, J. N.; Skakle, J. M. S.; Wardell, J. L. A triclinic polymorph of benzanilide: disordered molecules form hydrogen-bonded chains. Acta Crystallogr., Sect. C: Cryst. Struct. Commun. 2003, 59, o1-o3.

(12) (a) Das, U. K.; Kumar, A.; Ben-David, Y.; Iron, M. A.; Milstein, D. Manganese Catalyzed Hydrogenation of Carbamates and Urea Derivatives. J. Am. Chem. Soc. 2019, 141, 12962-12966. (b) Hou, C.; Jiang, J.; Li, Y.; Zhao, C.; Ke, Z. When Bifunctional Catalyst Encounters Dual MLC Modes: DFT Study on the Mechanistic Preference in Ru-PNNH Pincer Complex Catalyzed Dehydrogenative Coupling Reaction. ACS Catal. 2017, 7, 786-795. (c) Artús Suàrez, L.; Culakova, Z.; Balcells, D.; Bernskoetter, W. H.; Eisenstein, O.; Goldberg, K. I.; Hazari, N.; Tilset, M.; Nova, A. The Key Role of the Hemiaminal Intermediate in the Iron-Catalyzed Deaminative Hydrogenation of Amides. ACS Catal. 2018, 8, 8751-8762. 